\title{
Publisher's Note: Dynamic Stratification in Drying Films of Colloidal Mixtures [Phys. Rev. Lett. 116, 118301 (2016)]
}

\author{
Andrea Fortini, Ignacio Martín-Fabiani, Jennifer Lesage De La Haye, Pierre-Yves Dugas, Muriel Lansalot, \\ Franck D’Agosto, Elodie Bourgeat-Lami, Joseph L. Keddie, and Richard P. Sear \\ (Received 17 May 2016; published 2 June 2016)
}

DOI: $10.1103 /$ PhysRevLett.116.229902

This paper was published online on 18 March 2016 with an error in the affiliation list. The third affiliation should read as "Université de Lyon, Univ. Lyon 1, CPE Lyon, CNRS, UMR 5265, C2P2 (Chemistry, Catalysis, Polymers \& Processes), Team LCPP, Bat. 308F, 43 Bd. du 11 Novembre 1918, 69616 Villeurbanne, France.” The affiliation has been corrected as of 18 May 2016. The affiliation is incorrect in the printed version of the journal. 